\title{
Consumo, cenários comunicacionais e subjetividades juvenis ${ }^{1}$
}

\author{
Rose de Melo Rocha² \\ ESPM-SP \\ rrocha@espm.br \\ Josimey Costa da Silva 3 \\ Universidade Federal do Rio Grande do Norte \\ josimey@digizap.com.br
}

\begin{abstract}
Resumo: Esta comunicação articula reflexões das pesquisas "Imagens limiares e visualidades juvenis: imagética do consumo", sediada na $E S P M / S P$, e "Imagens de presença e de ausência: sentidos midiáticos da subjetividade juvenil", sediada na UFRN. O consumo é referência de uma epistemologia dos processos comunicacionais/midiáticos apoiada em investigações multimetodológicas. Buscam-se critérios para pensá-lo como sistema midiático com implicações em processos materiais e produtivos, $e$ também como regime afetual, dinâmica estésica e estética de produção de sentido vinculado a dimensões simbólicas. São investigadas práticas de consumo dirigidas ao corpo e relevantes nos processos de subjetivação de jovens urbanos tanto pela reprodução de padrões como pela criação de novas formas de apropriação de bens simbólicos.
\end{abstract}

Palavras-chave: Comunicação; consumo; juventude.

\footnotetext{
${ }^{1}$ Trabalho apresentado ao VI Encontro dos Núcleos de Pesquisa em Comunicação - NP Comunicação e Culturas Urbanas do XXX Congresso Brasileiro de Ciências da Comunicação INTERCOM 2007.

${ }^{2}$ Rose de Melo Rocha, doutora em Ciências da Comunicação (ECA/USP), com pós-doutorado em Ciências Sociais/Antropologia (PUCSP), é professora e pesquisadora do Programa de Mestrado em Comunicação e Práticas de Consumo da ESPM/SP, onde desenvolve a pesquisa "Imagens limiares e visibilidades juvenis: por uma imagética do consumo". Na PUCSP, participa da pesquisa internacional "Jovens Urbanos”. Tem várias publicações e ativa participação em congressos da área.

3 Josimey Costa da Silva, doutora em Ciências Sociais pela PUC/SP, é docente pela UFRN no Programa de Pós-Graduação em Ciências Sociais e no Curso de Comunicação Social, além de coordenadora do Grupo de Pesquisas Gemini - Análise e Pesquisa em Cultura, Processos e Produtos Midiáticos e membro do GRECOM - Grupo de Pesquisas da Complexidade. Tem diversos artigos e capítulos de livros publicados, além de co-organização do livro "Complexidade à flor da pele" (Sulinas, 2003).
} 


\begin{abstract}
The paper articulates reflections from two specific researches. Consumption is reference to an epistemological overview on mediatic processes, supported by multi-methodological investigations. It is perceived like a mediated system, implicating on both material and productive process, and also concerning to an affectionate regime, with aesthetic dynamics linked to symbolic dimensions. Consumptions practices are investigated, focusing the body and the processes of youngster's urbane subjectivities.
\end{abstract}

Keywords: Communication; consumption; youth.

Resumen: Ese artículo articula reflexiones de dos investigaciones particulares. La consumición es referencia a una descripción epistemológica de los procesos mediáticos, apoyada por aportes multimetodológicos. Se percibe como un sistema mediado, implicando en proceso material y productivo, y también tratando a un régimen afectual, con una dinámica estética ligada a dimensiones simbólicas. Las prácticas de consumo se investigan desde el cuerpo y de los procesos subjetivos propios a jóvenes urbanos.

Palabras-clave: Comunicación; consumición; juventud.

Résumé: Cete article analyse des réflexions provenient de deux recherches especific. La consommation est référence à une vue d'ensemble epistemologique sur des processus mediatic, soutenus par des investigations multi-méthodologiques. Elle est compreendue comme un système négocié, impliquant sur le processus matériel et productif, et concernant également à un régime affectueux, avec dynamiques esthétique liée aux dimensions symboliques. Des pratiques en matière de consommations sont étudiées, focalisant le corps et les processus des subjectivation courtois du jeune.

Mots clés: Communication; consommation; jeunesse.

\title{
Apontamentos iniciais: os princípios de diálogo
}

Este artigo tem por principal objetivo oferecer uma problematização de dinâmicas de consumo cultural juvenil articuladas a: 1 . um cenário reflexivo e epistemológico desde o qual se pensa o consumo a partir de práticas, estruturas e processos comunicacionais/midiáticos, constituindo regimes de ordem afetual, discursiva e cultural; e 2. um cenário empírico de caráter multimetodológico, articulado a etnografias do consumo, desde o qual se percebem, a partir de estudo de caso específico, as conflituosas e profícuas relações entre corpo, consumo e subjetividade juvenil. Para tanto, são retomadas iniciativas de cooperação 
interinstitucional e intercâmbios acadêmicos consolidados pelas autoras deste artigo em eventos científicos da área ${ }^{4}$.

Com esta observação, fica indicada a estrutura em que foi alicerçado este texto. Na primeira parte, ganha destaque o panorama conceitual proposto por Rose de Melo Rocha. Na segunda, revela-se a investida etnográfica de Josimey Costa. Ambas, dialogicamente estruturadas, comungam de uma preocupação nuclear: contribuir para a análise dos complexos fluxos comunicacionais articulados por dinâmicas contemporâneas de consumo. Igualmente, buscam investigar a larga demarcação que a cultura e as redes midiáticas imprimem às práticas de consumo em suas estratégias de produção mas, sobretudo, no modo como são percebidos, apropriados e narrados seus impactos por parte dos próprios consumidores, aqui concebidos como sujeitos culturais e políticos ativos e decisivamente atuantes neste processo, seja para confirmá-lo, seja para questioná-lo.

\section{“O consumo serve para pensar": o que pensar sobre o consumo?}

Somos seres forjados para o consumo. Somos seres forjados no consumo. Em que medida pode-se partilhar de tais supostos? De modo a aprofundar e desenvolver estas indagações, esta narrativa começa com apontamentos que, à primeira vista, poderiam parecer abstratos ou demasiadamente genéricos. Trata-se, contudo, de oferecer inicialmente os fundamentos reflexivos que, a seguir, se colocarão em diálogo com investigações de natureza empírica ou, ainda, daquelas extraídas desde observações etnográficas. Assim, mais do que apresentar, sob o formato de um arrazoado didático, metodologias possíveis para o estudo qualitativo

\footnotetext{
4 Destaca-se, em especial, a apresentação de papers em parceria na edição de 2006 do NP Comunicação e Culturas Urbanas e em encontros regionais (Intercom Nordeste) de 2006 e 2007. Ressalta-se, ainda, a inserção de Josimey Costa da Silva na etapa inicial da pesquisa internacional "Jovens Urbanos: Concepções de Vida e Morte", coordenada por Silvia Borelli e por Rose de Melo Rocha na PUC/SP. Originalmente intitulada "Concepciones de vida y muerte en jovens urbanos", esta pesquisa foi desenvolvida (2002-2004) por meio de convênio de cooperação internacional (PUCSP/Universidad Central de Bogotá) e contou com o auxílio pesquisa da FAPESP. A pesquisa prosseguiu numa etapa posterior (2005-2006). No momento atual (2007), a pesquisa propõe analisar em cooperação com a Universidad de Manizales, Colômbia intervenções culturais de jovens urbanos, como locus privilegiado de ações políticas e de cidadania. O corpus de pesquisa está constituído por ações culturais capitaneadas por grupos/coletivos juvenis com perfis auto-organizativos, auto-gestionários e extrainstitucionais que atuam em São Paulo, nas regiões sul e oeste. A coordenação é de Silvia Borelli, Rose de Melo Rocha e Rita Alves Oliveira junto ao Programa de Estudos PósGraduados em Ciências Sociais da PUCSP.
} 
do consumo, tem-se a clara intenção de assumir um ponto de partida epistemológico, partilhando alguns dos pressupostos gerais que têm orientado nossa investigação sobre o consumo, suas práticas, impactos e derivações sócio-comportamentais.

A afirmação que dá início a este tópico foi originalmente concebida pela antropóloga Mary Douglas em suas instigantes reflexões sobre as mercadorias e a antropologia do consumo, mas, sem sombra de dúvida, popularizou-se no Brasil e em boa parte da América Latina através das derivações a partir dela propostas pelo mexicano Néstor Garcia Canclini:

Comprar objetos, pendurá-los ou distribuí-los pela casa, assinalarlhes um lugar em uma ordem, atribuir-lhes funções na comunicação com os outros, são os recursos para se pensar o próprio corpo, a instável ordem social e as interações incertas com os demais, Consumir é tornar mais inteligível um mundo onde o sólido se evapora. (Canclini: 2005:65).

Portanto, não se trata, aqui, de reiterar o já dito. Antes, pretende-se utilizar a máxima "o consumo serve para pensar" como certo espelho invertido, em uma função especular bastante peculiar que permita, tomando a afirmação em sentido performativo, indagar: mas, enfim, o que desejamos, podemos ou devemos pensar sobre o consumo?

Necessário se faz, desde o princípio, ressaltar que a análise crítica aqui proposta não advoga refúgios de conforto, sejam eles advindos de raciocínios peremptórios ancorados em uma demonização da mídia e do consumo, sejam eles, em extrema oposição, respaldados por uma "consciência feliz" que nos pudesse, equivocadamente, assentir de per si com um caráter auto-regulador do mercado incluindo-se aqui sua dimensão simbólica - ou com uma suposta objetualidade pura de bens e mercadorias.

O olhar que se volta ao consumo afasta-se de aproximações exclusivamente materialistas ou daquelas de natureza unicamente metafísica, buscando, sempre a contrapelo, investigar os processos comunicacionais envolvidos no consumo e por ele articulados. Desde tais processos se constroem significados e sentidos e deles também, muito concretamente, eclodem e se agenciam conflitos, produzem-se enfrentamentos, rupturas, se estabelecem parcerias e se formulam proposições. Considerar o consumo lócus possível de ação cidadã não exclui, deste modo, a 
consideração de que, também a partir dele, seres podem se converter em objetos, subversões podem se tornar tendências culturais conformistas, singularidades podem se configurar mercadorias seriais, caráter pode ser comércio de cinismo ou bommocismo.

Para atingir esse objetivo, propõe-se uma perspectiva teórica que concebe o consumo como lócus privilegiado de constituição da subjetividade e a imagem como partícipe de uma inédita articulação do imaginário e da sociabilidade na atualidade. Interessa pensar o consumo através dos impactos sócio-culturais que se revelam nos fluxos de sentido e de sensação articulados pela produção e pela recepção de produtos midiáticos e dos significados grosso modo políticos da apropriação particularmente a juvenil - de alguns destes produtos e dinâmicas de consumo cultural. Para tal empreitada, é convocado um argumento de princípio que, em nossa concepção, poderá ser útil aos caminhos de problematização propostos.

Trata-se de incorporar às reflexões comunicacionais o papel seminal que as práticas de consumo, real e simbólico, desempenham nas sociedades contemporâneas. Vem-se constatando, em estudos de base empírica e qualitativa, o fato de nelas e a partir delas se constituírem identidades, tanto reativas quanto afirmativas. O consumo, de modo muito especial nos setores juvenis, afirma-se como referente fundamental para a conformação de narrativas, de representações imagéticas e de universos imaginários repletos de significação, das mais aterradoras às mais inspiradoras.

É urgente e relevante a demanda por estudos comunicacionais sistemáticos que articulem pesquisas voltadas à consolidação de uma análise das práticas de consumo sintonizada com a realidade nacional e sensível a sua inserção em dinâmicas mundiais, ou seja, a aspectos que lhe são específicos e a outros que se referendam e se confirmam em lógicas de maior abrangência e processos de partilha transterritorial. 
Os estudos desenvolvidos por Rose de Melo Rocha ${ }^{5}$ - e que têm nas práticas de consumo seu panorama reflexivo e seu primordial cenário de investigação - estão vinculados a dois tradicionais eixos de pesquisa no campo da comunicação, a Economia Política da Mídia e a Estética da Cultura de Massa, disciplinas que estão sob a responsabilidade da pesquisadora no Programa de Mestrado em "Comunicação e Práticas de Consumo”. A esta vinculação, correspondem opções teóricometodológicas bastante afinadas com toda uma trajetória de pesquisa na qual, muito fortemente, identificamos o papel primordial das imagens e dos regimes imaginários nos processos comunicacionais, e neste ponto defendemos tanto a dimensão antropológica da experiência estética, quanto o caráter arqueológico da mídia.

Deste modo, busca-se dar algumas indicações das linhagens com as quais se dialoga ao procurar desenvolver, delinear e discernir critérios interpretativos possíveis capazes de pensar o consumo tanto como sistema midiático implicado e implicando em estruturas econômicas, processos materiais e produtivos, mas, de maneira muito essencial, também como regime afetual aberto, dinâmica estésica e estética de produção de sentido ${ }^{6}$, estruturado por e estruturante de dimensões simbólicas, imateriais, porventura ideológicas, sempre discursivas e ideativas.

Com esta observação parece possível melhor articular a concepção de uma “imagética do consumo", terminologia que prevê uma interpretação menos focada em produtos ou serviços em si, mas que considera a inserção do consumo em toda uma cena ou rede midiática, rizomática e dinâmica. Desenvolvendo esta proposta, encontra-se que a lógica de produção, percepção e atribuição de sentidos e afetos característica de dinâmicas e processos de consumo pode ser percebida a partir dos rastros imaginários e de toda uma imagerie localizada na limiaridade entre a comunicação estetizada e a própria estetização do cotidiano.

\footnotetext{
5 Refiro-me à pesquisa "Imagens limiares...", anteriormente citada. Este projeto de pesquisa foca as teorias da imagem e da mídia desde a interface comunicação e práticas de consumo, investigando a natureza e o impacto das articulações entre visualidade, produção imaginária e dinâmicas de consumo, real e simbólico. Pretende-se, ainda, consolidar um aporte reflexivo capaz de oferecer operadores conceituais pertinentes à crítica midiática, focando a chamada "mídia jovem" e ampliando-se, posteriormente, através de estudos de campo vinculados ao largo espectro das imagens visuais publicitárias e das representações sobre e do jovem concernentes aos processos de comunicação urbana e a suas dinâmicas de consumo. ${ }^{6}$ Assume-se, neste aspecto, o diálogo com as proposições de Landowsky (1997).
} 
Segundo este ponto de vista, o consumo não pertence ao campo da irracionalidade, ainda que a ele se possam articular sintomas e patologias sociais. Estar-se-ia, na verdade, diante de um campo limítrofe, onde se articulam contaminações e fluxos, especialmente em contextos contemporâneos, marcados por processos de mundialização e mestiçagem cultural. Assim, este universo de limiaridades - cenários de intensidade e fluidez, consumo-panoramas, enfim desenha-se a partir de um incessante fluxo, perspectiva apresentada, com rara lucidez, pelo indiano Arjun Appadurai ao referir-se aos fluxos culturais, "às formas fluidas e irregulares" que comporiam as paisagens da cultura global, atuantes em situações, fenômenos e lugares de consumo:

A nova economia cultural global procura ser interpretada como uma ordem disjuntiva, superposta e complexa, que não pode mais ser interpretada em termos de modelos de centro e periferia existentes (...). A complexidade da atual ecnonomia global tem algo a ver com certas disjunções fundamentais entre a economia, a cultura e a política que mal começamos a teorizar.

Minha sugestão é que uma estrutura elementar para a análise dessas disjunções faça um estudo do relacionamento entre cinco dimensões do fluxo da cultura global que podem ser designadas da seguinte forma: (a) etnopanoramas; (b) midiapanoramas; (c) tecnopanoramas; (d) finançopanoramas; (e) ideopanoramas. (Appadurai, 1999: 312)

Recorrendo a Eric Landowsky (1997), talvez possamos perceber, compondo a gramatura desta tessitura de fluxos, o agenciamento mesmo de regimes de gosto. Esta semiótica dos gostos, dialogando com leituras sócio-analíticas e psico-analíticas do gosto, permite uma análise das dinâmicas afetuais estruturantes e estruturadas pela mídia e sobre os impactos sócio-culturais da produção de sentido articulada a dinâmicas da cultura do consumo.

Segundo o autor, o gosto é em um primeiro momento articulado à subjetividade. Em um primeiro momento, ele está associado ao sujeito que teria um “'gosto' pessoal e singular; um sistema próprio de "atrações e repulsões”. Assim, declarar o gosto é afirmação de identidade e estratégia de visibilidade, tomando parte de nossos rituais de encontro societal, de identificação e demarcação de diferença, nos quais por vezes se manifestam verdadeiros maníacos por declarar o gosto (Cf. Landowsky, 1997:99). Importa nesta definição do que se gosta, mas também, como se gosta do que se gosta. Podemos, por exemplo, citar o caso da admiração pelo bizarro, 
ela própria remetendo a uma autorização para se gostar de coisas que supostamente seriam do mais absoluto mau gosto.

Falando sobre esta construção do gosto, Eric Landowsky apresenta dois modos nucleares de sua configuração: de um lado, o princípio auto-suficiente do Gozo. O outro é aqui puramente objetal, interessando-nos apenas naquilo que nos faz gozar. Fundimo-nos com o objeto, nos tornamos unos, indivisíveis. De outro, o princípio relacional do Agradar. O outro é a instância super-poderosa à qual nos dirigimos. Se necessário for, nos tornamos nós próprios objetos para que melhor de nós ele possa gozar, para que, enfim, possamos agradá-lo. E aqui está a base do conflito. Queremos agradar, mas desejamos que, ainda assim, este Outro possa nos perceber como sujeito e não apenas nos desfrutar como objeto.

No primeiro modelo, o gosto de gozar, o encanto não está no novo do objeto, mas nas sensações que provoca ou dele decorrem; base auto-centrada e auto-erótica de satisfação. O gosto de agradar, por sua vez, implica que outros gostem... de mim! “Ao gosto de gozar o mundo sobrepõe-se, assim, à maneira de um segundo princípio regulador das relações que cada um entretém com seu meio ambiente, o gosto complementar de agradar a outrem" (Landowsky, 1997: 112).

Para além desta dupla imputação, na qual se atribuem características objetais a sujeitos e característica subjetivas a objetos, é possível localizar derivações mais complexas. Deste modo, com o "gozar" convive o "fruir", na suposição de um sujeito capaz de reconhecer o mundo como "espaço povoado por presenças sensíveis que produzam sentido, quer dizer, por sujeitos" (Landowsky, 1997: 121).

São duas as derivações do primeiro sistema: o "fruir", que é um "gozar subjetal"; o "aprazer", que é um "agradar objetal". Articulando-se no gosto a percepção e a propriocepção, prevêem-se, nestes termos, duas decisões possíveis: ser ele mesmo ou considerar o Outro. Desenha-se um eterno conflito ente gozo individual e êxito social, entre a aceitação (social) à distinção (pessoal).

Considerando o consumo lócus privilegiado de produção imagética e de constituição imaginária, a proposta de leitura aqui apresentada adota uma compreensão ampliada de tais fenômenos, pressupondo ser o consumo um fato cultural e uma manifestação imagética na qual se incluem uma ampla gama de 
imagens (imaginadas, visuais, olfativas, gustativas, táteis e sonoras). Localizam-se as dinâmicas e hábitos de consumo em um "para além” dos objetos e serviços - sem obviamente descartá-los - gerando sofisticadas e intensas articulações entre o campo simbólico e aquele especificamente mercadológico e, o que mais nos interessa, dando visibilidade ímpar às limiaridades e interconexões estabelecidas entre imagens midiáticas e universo imaginário.

Valendo-se de uma possibilidade reflexiva indicada por Arthur Kroker e David Cook (1991), defende-se que o consumo, fenômeno sensorial e cognitivo, opera na atualidade como um potente agenciador de "estados de espíritos" e não apenas de estilos-de-vida ou de estilos mentais. Ao abordarem esta problemática, os autores canadenses não excluem a noção de colonização. Mas esta seria, hoje, de outra ordem, a um só tempo neural e tecnológica. As imagens midiáticas seriam formas seriais de "modos de ser", espectros a serem alegre ou tristemente consumidos.

E como se daria, na produção e na recepção midiáticas, este agenciamento? Para investigar esta possibilidade seria interessante articular, ainda que de modo sintético, a correlação entre o quadro reflexivo acima apresentado e alguns dos operadores conceituais utilizados na análise da chamada "mídia jovem". Nesta definição incluem-se veículos ou encartes periódicos da mídia massiva voltados ao segmento juvenil, seja para tematizá-lo, seja para com ele dialogar na consideração de sua relevância nas dinâmicas de consumo.

Nesta aplicação, pode-se investigar algumas pistas reflexivas sobre a relação entre a eficácia comunicativa dos produtos midiáticos e a inserção do jovem em macro-processos de visibilidade. Assim, considera-se que elementos formais, aportes de conteúdo, projetos gráficos e linhas editoriais, articulando modos de ver, direcionamentos do olhar, imagens visuais e textuais, não só participam de modo relevante dos processos de visualidade e da juvenilização da cultura. Antes, oferecem poderosas senhas de acesso à aquisição de visibilidade sócio-cultural adquirida através da entrada em um muito peculiar universo juvenil. Este, cada vez mais perpassado pelos hábitos de consumo, é peça-chave na consolidação contemporânea do campo midiático. 
Dentre as estratégias adotadas para o estreitamento de vínculo com o público leitor, a mídia jovem propõe aos leitores a criação de todo um cenário ou cena interpretativa na qual se articulam - de modo seqüencial, relacional e pouco hierárquico - diferentes fragmentos de visualidade e variadas proposições de visibilidade. Tal recurso faz ressoar modelos ideais de comportamento, sugestões acerca de estilo de vida, parâmetros de apresentação corporal e, obviamente, um verdadeiro álbum imagético que se oferece como referencial para construções identitárias.

Se seguirmos o raciocínio proposto por Kroker e Cook (1991), poder-se-ia aí identificar a operação de uma estratégia midiática de estetização de princípios mercadológicos. Como já dito, para nossos autores, a mídia, enquanto aparato social abrangente, melhor coloniza a psicologia individual sendo um "determinador de estados de espírito" (mood setter). Coaduna-se, portanto, à propagação de imagens e produtos midiáticos um gerenciamento sensorial e comportamental decisivo, como se roupas, adereços, cd's e os próprios veículos compusessem uma curiosa bricolagem, um guia sobre como sentir e como se sentir.

Mais do que excesso ou pura e simples obscenidade das imagens, depreendem-se de discursos como os Kroker \& Cook uma pista analítica. Trata-se, em resumo, da inserção original das imagens na malha cultural, nas práticas de consumo e nas interações sociais contemporâneas, através da qual o consumo de imagens/sensações e de imagens/estilos-de-vida, lógica familiar a estratégias publicitárias, estende-se ao campo propriamente jornalístico. Este mercado de imagens é, também, uma imagem-mercado e um mercado de sensações. 
A auto-celebração midiática teorizada por autores como Michel Kokoreff ${ }^{7}$, ganha aqui uma imponderável articulação com hábitos e experiências de consumo cultural vivenciados no dia-a-dia. É-nos oferecida a possibilidade de assumir em relação à cena midiática uma função especular. Mirar-se nas imagens das celebridades televisivas, por exemplo, serve de mote tanto para iniciativas da mais pura adesão - quando fotos de atrizes oferecem acessíveis flashes de modos de se vestir e de se posicionar - quanto naquelas em que a imagem da estrela confirma a impossibilidade da identificação.

Por sua vez, peças publicitárias indicam regras de conduta aos jovens consumidores. São ali oferecidos modelos comportamentais nos quais as dinâmicas e conflitos cotidianamente experimentados recebem destinações e soluções possíveis. Gerenciando e colocando em pauta os assuntos relevantes e as soluções eficazes capazes de dar conta da inserção otimizada no mundo da visibilidade e do reconhecimento, a cena midíatica alimenta um poderoso agenciamento de subjetividades juvenis. Nestes "lugares especiais" adquirir aceitação e ser bem sucedido passa por saber administrar valores e expectativas, conferindo ao trato do sucesso e das frustrações um inegável valor de marca.

Em seus estudos sobre "consumo de mídia e identidades juvenis", Ronsini (2007) chega a uma preciosa formulação que aqui se quer destacar, como ponderação a este tópico que se finaliza e na articulação com o que virá a seguir. Vejamos sua argumentação:

O alargamento ou encolhimento da experiência simbólica inspirada no imaginário da mídia - dos sujeitos que consomem e

\footnotetext{
${ }_{7}$ Segundo Kokoreff, há uma tendência de que a televisão, o rádio, a imprensa e a publicidade dêem uma importância desmesurada a eles mesmos. Nesta leitura, esta tendência traduz uma transformação global dos modos sociais de representação e de troca, segundo a qual os meios de comunicação tornam-se seu próprio fim. Mobilizando os signos de sua excelência, exibindo a matriz técnica, a mídia se autonomiza, joga com a fascinação das imagens, em detrimento da significação. Não há inocência na incitação ao diálogo, à interação que ela promovem. Neste processo, que o autor compara a um "reaquecimento do social", já não se trata mais de mobilizar a opinião pública, mas, sim, de fazer do social um grande show: "pelo poder mágico da tela, os problemas da sociedade se metamorfoseiam em acontecimentos midiáticos". Desinvestidos de sua carga negativa, submetidos a um "tratamento emocional de superfície", estes problemas são absorvidos, persuadindo-nos, paradoxalmente, da necessidade e da grandeza do duplo midiático. (Kokoreff, Michel, "L'autocélébration de la télévision et ses paradoxes". Quaderni, $\mathrm{n}^{\circ}$ 4, primavera de 1988. Paris, CREDAP, Université Paris Dauphine, pp. 37-43).
} 
produzem os estilos juvenis depende da mediação (...) [das] redes locais de sociabilidade.

O interesse pela cultura globalizada não significa somente a subordinação à cultura da mídia que os leva a consumir produtos, programas e a reproduzir o repertório da música internacional, mas pode indicar o anseio pro novos padrões de vida, isto é, novas possibilidades materiais e simbólicas, diante da inconformidade dos jovens quanto às características de funcionamento das relações no entorno social. (Ronsini, 2007: 56-7).

\section{Corpo, consumo cultural e subjetividade juvenil}

Os jovens têm uma relação conflituosa com seus corpos, os quais, nem por isso, deixam de ser o meio fundamental da experimentação juvenil no mundo. Esse fato se inscreve nos corpos dos jovens de várias maneiras, particulares ou expressivas de padrões mais gerais. É possível considerar a juventude como categoria universal em face de traços de comportamento sócio-cultural tais como linguagem própria, gosto pela aventura, ligação com o presente e rejeição ao passado, recusa da experiência de outras pessoas como referencial, conflitos de geração, tendência à rebeldia, adesão ao movimento e ao jogo, busca pela auto-realização, exaltação da vida privada, adoção de ideais de beleza, amor e felicidade ${ }^{8}$.

As múltiplas expressões do corpo jovem são ícones do consciente e vitrines do inconsciente, percebidas por meio da pesquisa "Imagens de presença e de ausência: sentidos midiáticos da subjetividade juvenil”. Com caráter multimetodológico e pluridisciplinar, a investigação usa como base territorial a cidade de Natal, no Rio Grande do Norte, e constitui-se do mapeamento das formas e percursos de expressão das imagens na mídia a partir da análise de fenômenos e processos midiáticos locais norteadores do consumo cultural ${ }^{10}$. Os estilos de expressão verbal e apresentação visual dos jovens norte-rio-grandenses e suas imagens publicadas na mídia norte-riograndense são comparados a imagens obtidas em veículos do sudeste do país. O consumo está aqui assumido como uma prática

\footnotetext{
${ }^{8}$ Cf. Morin (1986).

9 Pesquisa coordenada por Josimey Costa da Silva, com período de realização de julho de 2006 a julho de 2007 e financiamento local pela Universidade Federal do Rio Grande do Norte. Bolsista PIBIC/Propeg: Patrícia Góes de Britto; estudantes participantes: Carlos Nathan e Priscila Adélia de Souza.

${ }^{10}$ Cf. trabalho proposto ao GT "Produção editorial e cultural" do IX Congresso Regional de Ciências da Comunicação, realizado em maio de 2007.
} 
social, como "o conjunto de processos socioculturais em que se realizam a apropriação e os usos dos produtos” (Canclini, 1999: 77), como uma forma tática de ação política ${ }^{11}$ em resposta a padrões esmagadores de comportamento social gerados pelo mercado e definidores em larga medida das relações dos consumidores com seus corpos.

O corpo humano nunca é apenas os seus próprios limites físicos e biológicos; ele se prolonga numa biologia periférica configurada pela cultura, nas roupas e nos objetos como óculos, bolsa, carro ${ }^{12}$. Conforme Montagu (1988: 296), os sentidos humanos podem ser classificados como de proximidade (tato, paladar e olfato) e de distância (visão e audição). Há, ainda, um sexto sentido, o da propriocepção (Baitello Jr., 2000: 81) que, do ponto de vista fisiológico, permite a percepção do próprio corpo, ou seja, percebe justamente o corpo que percebe. Esse sentido é a consciência do corpo e funciona como a consciência mental, isto é, num movimento recursivo de ida (percepção do mundo), volta (percepção de si) e ida-e-volta (percepção da própria percepção). A pele, da mesma forma, é um espelho voltado para o mundo, que olha para fora e para si próprio, recebe e devolve movimento e se relaciona com o surgimento do pensamento reflexivo.

O corpo sedia os odores, os sabores, as cores, as posturas, os gestos e os sons que dizem a si e aos outros informações sobre a sua condição fisiológica em gênero, idade, mudanças de estado, ação sofrida do meio ambiente, ação exercida sobre esse ambiente.

Quando o corpo se utiliza de artifícios para perceber mais ou agir concretamente mais sobre o mundo, recebe próteses: ferramentas, aparelhos, equipamentos, veículos de transporte; quando se utiliza de artefatos para expressarse ou ampliar a sua expressão simbólica, conta com o reforço das mídias da comunicação.

\footnotetext{
${ }^{11}$ Cf. Certeau (1994).

${ }^{12}$ Cf. Cyrulnik (1995) e Baudrillard (1973). 
Portanto, o corpo é em si a sede e um meio para a comunicação. É a mídia primária, o meio primordial de contato com o mundo de que os seres humanos se utilizam. Hoje, há enorme abundância de portadores técnicos de símbolos, ou as mídias da comunicação social de massa, mas isso não impede nem substitui a expressão do corpo. As sociedades ocidentais capitalistas valorizam sobremaneira as palavras como meio de expressão, mas elas são substitutas pobres das sensações complexas experimentadas intimamente. Daí, a recorrência a artifícios para a expressão da pele e sobre a pele: pinturas corporais, tatuagens, roupas. O desenvolvimento da expressão chegou ao paroxismo da moda atual, que mudou seu caráter de classe para outro, o de consumo. Ainda que reproduza padrões ou modelos industrias e uma lógica de mercado, esse consumo é capaz de também produzir sentido para grupos que compartilham seus códigos estéticos. Embora a proteção seja uma função das roupas, esta está subordinada à função semântica, pois o discurso é mais importante.

"Os símbolos não-verbais são os menos estáveis; conseqüentemente, sua manipulação tende a preceder a de símbolos verbais. O comportamento não-verbal é um meio poderoso de transmitir status social, especialmente por resultar quase sempre do hábito, em vez de ser fruto de decisões conscientes" (Crane, 2006: 266)

A indústria da moda envolve fascinação, glamour. A fascinação incita à imitação, suscita uma emoção socialmente generalizada que nasce da cisão profundamente atual entre o que cada um é e o que gostaria de ser. Embora também se dirija aos homens, a moda fala mais às mulheres, que passaram dos estereótipos de Eva (temível sedutora) e Amélia (doce rainha do lar) a uma tentativa de igualdade de gênero que lhe permite o uso de atributos da feminilidade antes imposto pelos homens. Por outro lado, a rigidez de determinados ideais de beleza e apresentação visual fez surgir novas formas de submissão especialmente cruéis com as mulheres jovens em busca de parceiros amorosos:

A moda passou a ser menos uma sucessão de volumes e muito mais um jogo de linhas sobre um espaço plano. (...) modismos que acentuam a aversão aos relevos epidérmicos e ao passeio rápido do olhar" (Sant'anna, 2001: 44).

O corpo da moda deve ser, portanto, magro, liso, uniforme, sem orifícios ou exsudações. Porém, dentro ou fora da moda, nu ou vestido, o corpo é um modo de 
relação com o mundo. A percepção é uma forma primária de conhecimento, mas não elementar nem superável, mas condição de existência do corpo que sintoniza o mundo. O mundo do homem é o mundo do corpo. A cultura é instituída quando a sociedade não dá respostas, como acontece no caso da morte. As expressões verbais em voga nos veículos impressos da mídia da comunicação social de massas revelam fartamente a negação da mortalidade pela exaltação da juventude: "pele de bebê"; "jovem para sempre"; "vigor da juventude" são algumas dessas expressões. Isso sugere um apagamento das linhas que vincam a face, a dissolução da escrita corporal expressiva das histórias individuais; faz-se dos corpos objetos e ama-se os objetos como se fossem si próprio. Os jovens são grandemente vulneráveis a essas sugestões. Protagonistas preferenciais e vítimas das imagens da mídia de mercado, correm o risco de viver como a sociedade ocidental capitalista preconiza: dependentes do mercado, auto-suficientes emocionalmente, solitários e viciados em coisas. Sempre na superfície e na efemeridade, tão erotizados no apelo publicitário que o caráter erótico se perde em meio à sua generalização.

Estes mesmos jovens, porém, usam a moda como forma de assumir posicionamentos políticos pelo uso de discursos não verbais. São eles,os jovens, que subvertem peças do vestuário, adornos, fazendo arranjos inusitados. São eles que utilizam esteticamente seus corpos como superfície do protesto. Seus códigos visuais dizem ao mundo dos seus pertencimentos e de suas perplexidades. O seu consumo reafirma os traços de sua subjetividade na composição do social.

A pesquisa "Imagens de presença e de ausência" tem acompanhado em Natal a divulgação de imagens relacionadas às práticas dos jovens na cidade em dois jornais diários de circulação estadual, além de observar a expressão dessas imagens nos estilos de apresentação visual e alguns hábitos de comportamento público relacionados a entretenimento e fruição estética em locais freqüentados por jovens. Alguns temas-chave são operadores para a análise: o primeiro é juventude, com base em expressões de auto-imagem corporal, conflito geracional / rebeldia, pertencimentos, percepção da juventude, deslocamento / transformação e mercado de trabalho. Um segundo é inserção social, com destaque para relação com trabalho e pendência, aceitação /preconceito sobre estilos, gênero (diferenças), sexualidade e compromissos / relacionamento. Também há sondagem de aspectos da percepção da 
violência a partir das representações sobre cidade, responsabilidade (institucional / social), experimentação pessoal, localização de eventos, atitude pessoal e presença na mídia / suportes.

O cotidiano aparece na menção a situações corriqueiras, estudo, trabalho, esporte, hobby, fruição do tempo, atividades com família / amigos e atividades agradáveis / desagradáveis. O último tema, consumo cultural, é visto por meio dos aspectos ídolos, atividades de consumo mais freqüentes, relação com TV, cinema / vídeo, livros, jornal / revista, gibis, rádio, música, produção cultural, Internet, videogame, estilo / roupa e acessórios, influências sobre o comportamento e interferências corporais. A observação etnográfica originou também a formação de um banco de imagens fotográficas para análise das formas/estilos de apresentação visual dos jovens, com consideração das roupas, acessórios, modificações corporais e objetos portados, além da postura e expressão facial.

A pesquisa está em andamento, agora na parte de interpretação dos dados. No clipping feito com as edições dos jornais "Diário de Natal" e "Tribuna do Norte", publicadas durante os 60 dias da coleta, pôde ser observada inicialmente uma polarização na representação dos jovens natalenses, tanto nos textos quanto nas imagens fotográficas. Os jornais tendem a apresentá-los em duas categorias distintas: de um lado, estão os jovens de padrão médio-alto de consumo, mostrados com características positivas (beleza, apelo sexual, inteligência e felicidade), em imagens que reforçam a saúde e o vigor do corpo; do outro, os jovens padrão baixo de consumo são apresentados como violentos e perigosos para a sociedade, os corpos se apresentam contraídos, sem luz favorável à sua valorização imagética. Na comparação com as entrevistas, constatou-se que há uma disparidade entre a imagem deles apresentada pela mídia e como eles de fato se percebem; os jovens socialmente valorizados não vêem a representação de seus conflitos na mídia local, a não ser em situações exemplares, e os jovens de estratos pobres não têm representação de seu cotidiano ou de suas qualidades positivas.

A mídia impressa publicada no sudeste do país está sendo usada como termo de comparação para a generalização ou especificidade de traços culturais. Algumas confluências entre representações e comportamentos dos jovens urbanos são 
perceptíveis. As revistas Trip ( $\mathrm{n}^{\circ}$. 153) e TPM ( $\left.\mathrm{n}^{\circ} .63\right)$, ambas de março de $2007^{13}$, reafirmam, do ponto de vista da imagem dos jovens que elas simbolizam, a idéia de linguagem própria, tendência à rebeldia, gosto pela aventura, assim como adesão ao movimento e ao jogo. Essa tendência também é notada entre os leitores que se manifestam na seção de cartas da FolhaTeen ${ }^{14}$. Em Natal, conflitos como o geracional e o inconformismo aparecem mais entre os entrevistados de baixo poder aquisitivo. Tanto entre os jovens natalenses como entre os do sudeste retratados na mídia, a opção por gêneros musicais aparece como definidora de pertencimentos a estratos sociais e grupos de consumo específicos, com uma tendência ao gosto por bandas e estilos estrangeiros entre os de maior poder aquisitivo, enquanto que os de menor poder ou de repertório cultural mais restrito aderem aos estilos regionais massificados.

Quanto aos estilos de vestir, de apresentação visual, considerados na comparação entre as imagens da mídia e os jovens observados em seus locais de lazer e encontro, é notável certa padronização no repertório estilístico e nos modos de usar roupas e acessórios. Em Natal, assim como mostram as publicações do sudeste, surgem agrupamentos por consumo simbólico. Foram encontrados jovens com roupas, acessórios e interferências corporais caractertísticas de estilos tais como rastafáris, "manos", funkeiros, surfistas, "patricinhas" e "mauricinhos", com a devida adaptação do vestuário ao clima quente (mais decotes, camisetas sem manga, bermudas). As cores usadas em geral são claras e variadas, vibrantes, mas o jeans é recorrente e o preto é bastante usado por roqueiros e metaleiros, como em todo o mundo ocidental.

Griffes são ostentadas entre jovens de mais alto poder econômico, mas as formas de uso são menos diversificadas que entre os jovens de médio e baixo poder aquistivo. Estes últimos mostram mais o corpo quando em locais de lazer, com mulheres usando mais minissaias e decotes amplos, e homens usando bermudas e camisetas-regata. Na observação etnográfica realizada em uma casa noturna de reggae e em um shopping center de Natal ${ }^{15}$, essa diferença apareceu bem marcada.

\footnotetext{
13 Publicadas em São Paulo, pela editora Trip, com circulação nacional.

14 Suplemento semanal do jornal Folha de S.Paulo. Edições consultadas nesta etapa da pesquisa: 12/02/2007 e 18/03/2007, pp. 02.

15 Estação Ribeira em 09/03/2007 e Midway Mall em 10/03/2007.
} 
No primeiro local, era grande a variedade de cortes, penteados e adereços de cabelo, acessórios, bolsas e padrões de estamparia usados pelos jovens. No segundo, havia padronização de cabelos lisos, estilos de acessório, calça jeans justa, tênis para homens e sandálias de salto alto para mulheres, independentemente da idade.

"Na moda 'de consumo', que substituiu a de classe, há muito mais diversidade estilística e muito menos consenso sobre o que está 'em voga' em determinada época. Em vez de se orientar para o gosto das elites, a moda de consumo incorpora gostos e interesses de grupos sociais de todos os níveis. (...) A moda de rua é criada por subculturas urbanas e oferece muitas idéias para modismos e tendências" (Crane, 2006: 273-274).

Ilustrativo disso é o fenômeno recente de proliferação dos sites de "street style", com fotos de anônimos com estilos de apresentação visual diferenciada, o que tem influenciado as criações da indústria da moda. O que está nas ruas inspira estilistas e volta ao mercado com assinatura ${ }^{16}$. Assim, os consumidores mais abastados terminam por usar aquilo que os menos abastados inventam para substituir o consumo que não podem exercer, num ciclo de retroalimentação simbólica e econômica incessante.

\section{Referências bibliográficas}

ARJUN, Appadurai. "Disjunção e diferença na economia cultural global”. In. FEATHERSTONE, Mike (org.). Cultura Global. Petrópolis: Vozes, 1999.

BAITELLO JR., Norval. O animal que parou os relógios. São Paulo: Anna Blume, 1997.

BAUDRILLARD, Jean. O sistema dos objetos. São Paulo: Perspectiva, 1973. (Col. Debates)

BETH, Hanno / PROSS, Harry. Introducción a la ciencia de la comunicación. Barcelona: Anthropos, 1990.

CANCLINI, Néstor G. Consumidores e cidadãos: conflitos multiculturais da globalização. 4a ed. Rio de Janeiro: Ed. da UFRJ, 2005.

CERTEAU, Michel de. A invenção do cotidiano. Petrópolis/RJ: Vozes, 1994.

\footnotetext{
${ }^{16}$ Cf. reportagem "A moda nômade dos blogs", na coluna "Última moda", de Alcino Leite
} Neto, publicada em 25/05/2007, no jornal Folha de S. Paulo, p. E9. 
CRANE, Diana. A moda e seu papel social: classe, gênero e identidade. São Paulo: SENAC, 2006.

CYRULNIK, Boris. Os alimentos do afeto. São Paulo: Ática, 1995.

LANDOWSKY, Eric e FIORIN, José Luiz (eds.). O gosto da gente, o gosto das coisas. São Paulo: EDUC, 1997.

MONTAGU, Ashley. Tocar: o significado humano da pele. São Paulo: Summus, 1988.

MORIN, Edgar. Cultura de massas no século XX: o espírito do tempo - Neurose. Vol. I. Rio de Janeiro: Forense Universitária, 1986.

RONSINI, Veneza. Marcadores de sentido. Consumo de mídia e identidades juvenis. Porto Alegre: Sulina, 2007.

SANT'ANNA, Denise Bernuzzi de. Corpos de passagem: ensaios sobre a subjetividade contemporânea. São Paulo: Estação Liberdade, 2001.

SERRES, Michel. Variações sobre o corpo. Rio de Janeiro, Bertrand Brasil, 2004. 